\title{
On-site Catalytic Determination of Trace Manganese in Fresh Water Using Oxidation of Malachite Green with Periodate
}

\author{
Junpei Shindo, $* * *$ Junji KoJIma,* Yasutada Suzuki,*** and Susumu KawaKubo*† \\ *Interdisciplinary Graduate School of Medicine and Engineering, University of Yamanashi, \\ Takeda, Kofu 400-8511, Japan \\ **Environmental Technology Center Co., Ltd., 1-8 Kanda-Ogawamachi, Chiyoda, Tokyo 101-0052, Japan \\ ***Center of Instrumental Analysis, University of Yamanashi, Takeda, Kofu 400-8511, Japan
}

\begin{abstract}
An on-site determination method for trace manganese has been developed using the manganese-catalyzed oxidation of Malachite Green (MG) with potassium periodate. Absorbance measurement of MG was carried out using a laboratory-made palm-top size colorimeter with a red-green-blue light-emitting diode. The reciprocal value $(1 / \tau)$ of the reaction time at a fixed absorbance value for red light was chosen as a kinetic parameter for simple on-site analyses. The value of $1 / \tau$ was proportional to the concentration of manganese in the range of $2-20 \mu \mathrm{g} \mathrm{L}^{-1}$. At a reaction temperature $(T)$ of $20^{\circ} \mathrm{C}$ or more, manganese was determined within a reaction time of $25 \mathrm{~min}$. The calibration equation was approximated by $1 / \tau=(a T+b)[\mathrm{Mn}]+(c T+d)$, where $a$ to $d$ were constants in a range of $10-40^{\circ} \mathrm{C}$. The two equations for $30^{\circ} \mathrm{C}$ (for the laboratory-preparation of the calibration equation) and $T$ give the value of $1 / \tau$ at $30^{\circ} \mathrm{C}$ as $1 / \tau_{\mathrm{f}}=(30 a+b)(1 / \tau-c T-d) /$ $(a T+b)+30 c+d$. Without any temperature control, $1 / \tau_{\mathrm{f}}$ can be calculated by this equation and measurements of $1 / \tau$ and $T$. The calculation introduced analytical errors of within $1 \mu \mathrm{g} \mathrm{L}^{-1}$. The proposed method was successfully applied to tap-, river- and lake-water samples.
\end{abstract}

(Received February 5, 2011; Accepted April 9, 2011; Published May 10, 2011)

\section{Introduction}

An on-site analytical technique is increasingly required for the monitoring and control of industrial processes and environmental pollutions. This technique is useful to survey local or temporal change of water quality. For manganese, its concentration is controlled so as to prevent water discoloration, black staining and bitter metallic taste., ${ }^{1,2}$ WHO recommendations give a guideline value of $0.4 \mathrm{mg} \mathrm{L}^{-1}{ }^{1}$ The U. S. EPA guideline ${ }^{2}$ regulates the concentration of manganese at $0.05 \mathrm{mg} \mathrm{L}^{-1}$. A Japanese Ministry notification ${ }^{3}$ encourages water suppliers to control the concentration to be less than $0.01 \mathrm{mg} \mathrm{L}^{-1}$. Concentrations of manganese in fresh water are quite low: $0.004 \mathrm{mg} \mathrm{L}^{-1}$, as an estimated mean for stream water in the world. ${ }^{4}$ A detection limit of $0.02 \mathrm{mg} \mathrm{L}^{-1}$ is performed by a commercial portable colorimeter using 1-(2-pyridylazo)2-naphthaol as a colorimetric reagent. ${ }^{5}$ However, a toxic cyanide solution is used in this method. A detection limit of $0.5 \mu \mathrm{g} \mathrm{L}{ }^{-1}$ was reported for the on-site monitoring of manganese in seawater by a cathodic stripping voltammetry using a boron-doped diamond electrode and preconcentration under ultrasonic irradiation. ${ }^{6}$ In this method, UV irradiation for $24 \mathrm{~h}$ is adopted for the decomposition of interfering organic substances, such as humic acid. It is not adequate for on-site analysis. A catalytic method based on the preconcentration of manganese on filter paper with a collector reagent and an indicator reaction of manganese-catalyzed oxidation of

† To whom correspondence should be addressed.

E-mail: akawakubo@yamanashi.ac.jp $3,3^{\prime}, 5,5^{\prime}$-tetramethylbenzidine with periodate on the surface of the paper was proposed for the spectrophotometric determination or visual detection. ${ }^{7}$ This method has potential to use a sensitive on-site determination of manganese at $5 \times 10^{-3} \mu \mathrm{g} \mathrm{L}^{-1}$, but no discussion was found concerning the influence of the reaction temperature on the analytical performances. Based on a kinetic approach, we redesigned the catalytic method using the manganese-catalyzed oxidation of Malachite Green with periodate $^{8}$ for on-site analysis, and applied this method to the determination of trace manganese in natural fresh-water samples. A kinetic parameter for the determination of manganese was selected for simple on-site analyses. The analytical technique of temperature control-free was studied for the convenience of on-site work. A linear dependency of the reaction temperature on the slope and the intercept of the calibration equation of manganese was found, and it introduced an algorithm to calculate the values of $1 / \tau$ at a fixed reaction temperature without controlling the reaction temperature on-site. The calculation also omitted the on-site preparation of the calibration curve.

\section{Experimental}

\section{Reagents and samples}

All chemicals were of analytical reagent grade. Ultrapure water with $\geq 18 \mathrm{M} \Omega \mathrm{cm}$, prepared by a Millipore Simpli Lab-UV system, was used throughout. A manganese stock standard solution (0.500 $\left.\mathrm{g} \mathrm{Mn}(\mathrm{II}) \mathrm{L}^{-1}\right)$ was prepared by dissolving manganese metal powder (Wako Pure Chemical Industries, purity $>99.99 \%$ ) with $\mathrm{HNO}_{3}$ and heating with $9 \mathrm{M} \mathrm{H}_{2} \mathrm{SO}_{4}$ to 
expel excess $\mathrm{HNO}_{3}$, and diluting with water. Working standard solutions were prepared by diluting the stock solution with water. A Malachite Green (MG) stock solution $(2.2 \mathrm{mM})$ was prepared by dissolving the reagent $\left(N, N, N^{\prime}, N^{\prime}\right.$-tetramethyl- $4,4^{\prime}$ diaminotriphenylcarbenium oxalate, Wako Pure Chemical Industries) with water. MG working solutions were prepared by diluting the MG stock solution with water, and was used within 3 weeks.

\section{Apparatus}

On-site determination of manganese was carried out using a laboratory-made portable colorimeter $(10 \times 7 \times 5 \mathrm{~cm}, 280 \mathrm{~g})$ equipped with a $10-\mathrm{mm}$ glass cell. ${ }^{9}$ This colorimeter has a red-green-blue LED light source (three light emitters, Nichia NSTM515M) and a photodiode (Hamamatsu Photonics, S2386-18K) for the absorbance measurement. The absorbance value was displayed on a liquid-crystal display. Red light with a maximum emission wavelength of $630 \mathrm{~nm}$ and a spectral band width of $25 \mathrm{~nm}$ was used for the determination. In order to evaluate the proposed method, the absorbance measurement was carried out with a double-beam spectrophotometer (Shimadzu, UV-2550) equipped with a 10-mm glass cell. The cell was controlled at a constant temperature within $0.1^{\circ} \mathrm{C}$ by circulating water from a thermostated water bath to the cell chamber. Manganese was also determined at $279.5 \mathrm{~nm}$ with an graphite-furnace atomic absorption spectrometer (Shimadzu, AA-6800). A thermometer with a precision of $0.2^{\circ} \mathrm{C}$ was used to measure the on-site solution temperature. A stopwatch with a precision of $1 / 10$ of a minute was used to measure the reaction time on-site.

\section{Analytical procedure}

On-site determination. Before the on-site analysis, reagent solutions, water and a sample were placed in the same place to keep the solution temperature the same $\left(T,{ }^{\circ} \mathrm{C}\right)$. An aliquot of the sample was placed into a $20-\mathrm{mL}$ glass test tube and diluted to $3 \mathrm{~mL}$ with water. Thereafter, $0.5 \mathrm{~mL}$ of an acetate buffer solution containing $6.2 \mathrm{M}$ acetic acid and $0.77 \mathrm{M}$ sodium acetate and $0.4 \mathrm{~mL}$ of $0.22 \mathrm{mM} \mathrm{MG}$ were added to the solution. The reaction was started by adding $0.1 \mathrm{~mL}$ of a $0.017 \mathrm{M}$ potassium periodate solution. The reacting solution was transferred into the cell and the absorbance for the red light against water was monitored. The reaction time $(\tau, \mathrm{min})$ giving an absorbance of 0.785 was measured using the colorimeter. The value of $1 / \tau$ at $30^{\circ} \mathrm{C}$ was calculated by substituting values of $T$ and $1 / \tau$ in Eq. (15) (see the Algorithm for on-site determination without control of the reaction temperature section). In the laboratory, using manganese working standard solutions, the calibration curve at a reaction temperature of $30^{\circ} \mathrm{C}$ was previously constructed by plotting $1 / \tau$ against the concentration of manganese.

Loratory determination. For a comparison, manganese was determined in the laboratory. Before the analysis, reagent solutions and water were placed in the thermostated water bath in order to keep the solution temperature at $30^{\circ} \mathrm{C}$. An aliquot ( $\leq 3 \mathrm{~mL})$ of the water sample was placed into the test tube and, for adjusting the temperature, was left standing for about $3 \mathrm{~min}$ in the bath. The preparation of the reacting solution was followed by the procedure of the on-site determination procedure. The absorbance was measured at $615 \mathrm{~nm}$ by a spectrophotometer. The value of $\tau$ giving an absorbance of 1.60 was measured in the laboratory determination.

For an acidified sample, the sample was neutralized with a 0.1 or $1 \mathrm{M} \mathrm{NaOH}$ solution before adding water. The same amounts of acid (e.g., $\mathrm{HNO}_{3}$ ) and $\mathrm{NaOH}$ were added with the manganese working standard solution for constructing of a calibration curve.

\section{Results and Discussion}

\section{Reaction mechanism of oxidation of $M G$ with periodate}

The reaction mechanism of the oxidation of MG was studied to find a kinetic parameter suitable for the on-site determination of manganese. The discoloration of MG with periodate accompanied an induction period. The presence of induction period was associated with a slow rate-determining step for the formation of reactive $\mathrm{Mn}(\mathrm{III}), \mathrm{Mn}(\mathrm{VII})$ or intermediates, e.g., nitrilotriacetate complexes. ${ }^{10}$ A kinetic study about the chromium-catalyzed oxidation of MG with oxalic acid suggested that the induction period was caused by the formation of reactive chromium(VI) oxalate complexes or by the predominant oxidation of colorless MG (tertiary alcohol forms) equilibrated with colored MG. ${ }^{11}$ The formation of such complexes was not accepted for our reaction system, because no complexing agent for manganese was added. Under the reaction condition described in the Analytical procedure section, an increase of the reaction time between $\mathrm{Mn}(\mathrm{II})$ and periodate decreased the induction period. At $5 \mu \mathrm{g} \mathrm{L}^{-1}$ of $\mathrm{Mn}(\mathrm{II})$, the length of the induction period decreased to $30 \%$ for a reaction time of $5 \mathrm{~min}$ between them. At $3 \mu \mathrm{g} \mathrm{L}^{-1}$, it decreased to $60 \%$ for $20 \mathrm{~min}$. The reaction of $0.05 \mathrm{mM}\left(2.75 \mathrm{mg} \mathrm{L}^{-1}\right)$ of $\mathrm{Mn}(\mathrm{II})$ with $0.4 \mathrm{mM}$ potassium periodate at $\mathrm{pH} 3.8$ and $30^{\circ} \mathrm{C}$ produced a pink product, identified as permanganate ions spectrophotometrically. About $75 \%$ of $\mathrm{Mn}(\mathrm{II})$ changed to $\mathrm{Mn}$ (VII) within a reaction time of $30 \mathrm{~min}$. These results suggest a probable reaction process with the induction period; a slow oxidation of $\mathrm{Mn}$ (II) to $\mathrm{Mn}(\mathrm{III})$ and a catalytic cycle between $\mathrm{Mn}(\mathrm{III})$ and $\mathrm{Mn}(\mathrm{VII})$. The decrease of the induction period by the oxidation of $\mathrm{Mn}$ (II) with periodate was found in our experiment, but it required a long oxidation time at a lower concentration of $\mathrm{Mn}$ (II). In addition, the induction period did not disappear completely by the addition of permanganate ions as $5 \mu \mathrm{g} \mathrm{L}{ }^{-1}$ of $\mathrm{Mn}$ (II). Therefore, in this study, the discoloration process of $\mathrm{MG}$ accompanying the induction period was used for an on-site determination. Based on the above findings and the reaction process of chromium-catalyzed oxidation of $\mathrm{MG}$ in the presence of oxalate, ${ }^{11}$ the manganese-catalyzed oxidation of MG with periodate is represented as the following reactions:

$$
\begin{aligned}
& 2 \mathrm{Mn}(\mathrm{II})+\mathrm{IO}_{4^{-}} \longrightarrow 2 \mathrm{Mn}(\mathrm{III})+\mathrm{IO}_{3^{-}}, \\
& 2 \mathrm{Mn}(\mathrm{III})+4 \mathrm{IO}_{4^{-}} \longrightarrow 2 \mathrm{Mn}(\mathrm{VII})+4 \mathrm{IO}_{3^{-}}, \\
& 2 \mathrm{Mn}(\mathrm{VII})+2 \mathrm{MG} \longrightarrow 2 \mathrm{Mn}(\mathrm{III})+2 \mathrm{MG}_{\mathrm{ox}} .
\end{aligned}
$$

$\mathrm{MG}_{\mathrm{ox}}$ denotes colorless oxidation product(s) of MG. Reaction (1) is slow, and thereby gives an induction period. The overall reaction of reactions (2) and (3) is

$$
\mathrm{MG}+2 \mathrm{IO}_{4}^{-} \longrightarrow \mathrm{MG}_{\mathrm{ox}}+2 \mathrm{IO}_{3}^{-} .
$$

This is an indicator reaction used for the determination of manganese. In the analytical procedure, the potassium periodate was added finally in order to minimize the effect of reaction (1) on the induction period.

\section{Kinetic parameter for on-site determination of manganese}

The length of the induction period ${ }^{8}$ or the reaction rate $^{12}$ in the discoloration of MG with periodate was measured as the kinetic 


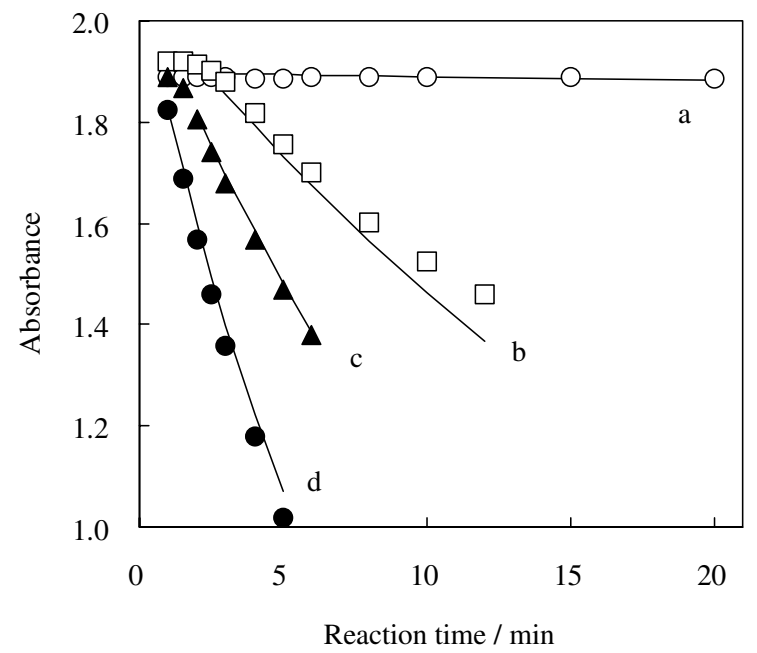

Fig. 1 Reaction curves for the reagent blank (a), 5 (b), 10 (c) and $20 \mu \mathrm{g} \mathrm{Mn}$ (II) $\mathrm{L}^{-1}$ (d) under the conditions $2.2 \times 10^{-5} \mathrm{M} \mathrm{MG}-4.2 \times$ $10^{-4} \mathrm{M} \mathrm{KIO}_{4}$ at $\mathrm{pH} 3.8$ and $30^{\circ} \mathrm{C}$. Symbols and lines indicate the experimental and calculated absorbance, respectively.

parameter for the laboratory determination of manganese. The end of the induction period is not clear. Therefore, the measurement of the induction period requires the reaction curve printed or chart-recorded. However, it is not convenient in on-site analysis. The determination based on the measurement of the discoloration rate or the absorbance at a fixed reaction time required a high reaction temperature $\left(50^{\circ} \mathrm{C}\right) .{ }^{12,13}$ Warming of the reacting solution is not suitable for field survey. Therefore, based on the reaction kinetics, we studied to find a kinetic parameter for the on-site determination, although the presence of the induction period was not exactly explained by reactions (1) to (3) proposed in the above section.

In the presence of a sufficient concentration of periodate, reaction (4) gives

$$
-\mathrm{d}[\mathrm{MG}] / \mathrm{d} t=k_{1}[\mathrm{MG}]
$$

where $k_{1}$ is an apparent rate coefficient. If $k_{1}=k_{2}[\mathrm{Mn}]+k_{3}$ ( $k_{2}$ and $k_{3}$ are constants), the integral form of Eq. (5) is

$$
\ln \left([\mathrm{MG}]_{\mathrm{o}} /[\mathrm{MG}]\right)=\left(k_{2}[\mathrm{Mn}]+k_{3}\right)(t-\delta),
$$

where $[\mathrm{MG}]_{\mathrm{o}}$ and $\delta$ denote an initial concentration of MG and the length of the induction period, respectively. From previous work, ${ }^{8}$ the relationship between [Mn] and $\delta$ is represented as

$$
1 / \delta=k_{4}[\mathrm{Mn}]+k_{5}
$$

where $k_{4}$ and $k_{5}$ are constants. It is noted that the introduction of Eq. (7) and the term of $t-\delta$ in Eq. (6) was based on experimental results, and not on the kinetic equations. From Eqs. (6) and (7),

$$
\begin{aligned}
\ln \left([\mathrm{MG}]_{0} /[\mathrm{MG}]\right)=( & \left(k_{2}[\mathrm{Mn}]+k_{3}\right) t- \\
& \left(k_{2}[\mathrm{Mn}]+k_{3}\right) /\left(k_{4}[\mathrm{Mn}]+k_{5}\right)
\end{aligned}
$$

or

$$
\begin{array}{r}
1 / t=\left(k_{2}[\mathrm{Mn}]+k_{3}\right) /\left\{\ln \left([\mathrm{MG}]_{0} /[\mathrm{MG}]\right)+\right. \\
\left.\left(k_{2}[\mathrm{Mn}]+k_{3}\right) /\left(k_{4}[\mathrm{Mn}]+k_{5}\right)\right\} .
\end{array}
$$

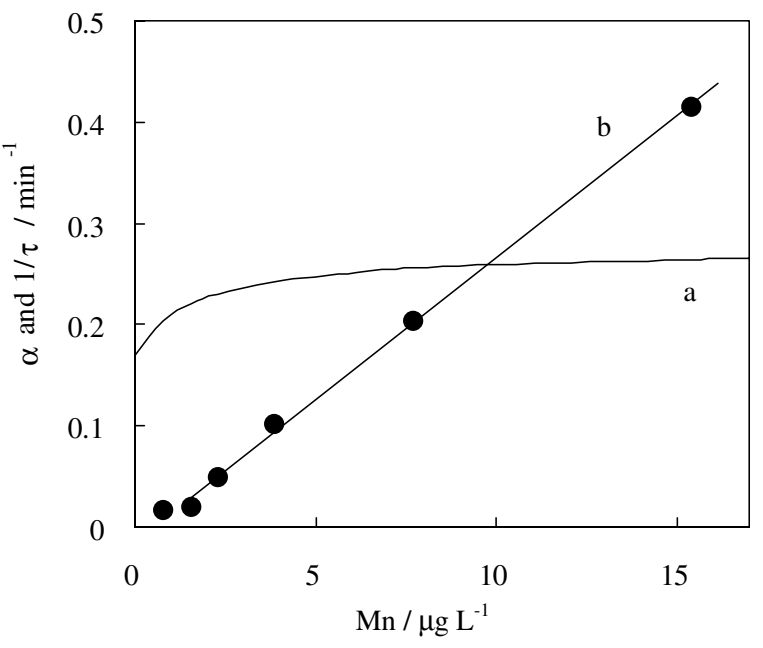

Fig. 2 Effect of the concentration of manganese on $\alpha$ (a) and $1 / \tau$ (b) under the reaction conditions shown in Fig. 1. The symbol of $\alpha$ is defined in the text.

The values of $k_{4}$ and $k_{5}$, experimentally obtained by Eq. (7), were substituted into Eq. (9), and then the values of $k_{2}$ and $k_{3}$ were calculated from experimental data for the reaction curves shown in Fig. 1. The experimental data were obtained by the procedure for the laboratory determination described in the Analytical procedure section. Calculated results (curves in the figure; $[\mathrm{MG}]_{\mathrm{o}}=2.2 \times 10^{-5} \mathrm{M}, \quad k_{2}=0.0067, \quad k_{3}=0.00041$, $\left.k_{4}=0.062, k_{5}=0.10\right)$ fitted the experimental data (symbols) within an absorbance deviation of $10 \%$, indicating the validity of Eqs. (8) or (9). When $\alpha$ denotes the term of $\ln \left([\mathrm{MG}]_{\mathrm{o}} /[\mathrm{MG}]\right)+$ $\left(k_{2}[\mathrm{Mn}]+k_{3}\right) /\left(k_{4}[\mathrm{Mn}]+k_{5}\right)$ in Eq. (9), this value became constant within a deviation of about $10 \%$ in $[\mathrm{Mn}] \geq 3 \mu \mathrm{g} \mathrm{L}^{-1}$, as shown in Fig. 2(a). When $\tau$ denotes the reaction time at a fixed concentration of MG, Eq. (9) becomes

$$
1 / \tau=S[\mathrm{Mn}]+B
$$

where $S=k_{2} / \alpha$ and $B=k_{3} / \alpha$. Figure 2(b) shows the relationship between $1 / \tau$ and $[\mathrm{Mn}]$ at $30^{\circ} \mathrm{C}$. Its linearity supports the validity of Eq. (10). However, a non-linear part in $[\mathrm{Mn}]<2 \mu \mathrm{g} \mathrm{L}^{-1}$ is not ascribed by a change of the $\alpha$ value, because the calculated change increases the value of $1 / \tau$ up to only $20 \%$. The measurement of $\tau$ is easy in on-site analysis. Therefore, $1 / \tau$ was adopted as a kinetic parameter for the on-site determination of manganese.

Algorithm for on-site determination without control of the reaction temperature

The kinetic method generally requires rigid control of the reaction temperature for a precise determination. The control of the temperature or the preparation of a calibration curve at an on-site temperature is a tedious operation in a field survey. In addition, commercial portable temperature-controllers have often exhibited poor portability or precision. Therefore, we studied the algorithm giving $1 / \tau$ at a fixed temperature from that measured at various on-site temperatures. Table 1 gives the slope $(S)$, intercept $(B)$ and correlation coefficient $(r)$ of the calibration equation for different reaction temperatures $\left(T,{ }^{\circ} \mathrm{C}\right)$. The relationship between $S$ (or $B$ ) and $T$ can be approximated by

$$
S=1.07 \times 10^{-3} T-1.5 \times 10^{-3} \quad(r=0.993),
$$


Table 1 Calibration equations at different reaction temperatures

\begin{tabular}{|c|c|c|c|}
\hline $\begin{array}{c}\text { Reaction } \\
\text { temperature } /{ }^{\circ} \mathrm{C}\end{array}$ & $\begin{array}{c}\text { Slope } S / \\
\mathrm{L} \mu \mathrm{g}^{-1} \mathrm{~min}^{-1}\end{array}$ & $\begin{array}{c}\text { Intercept } B / \\
\min ^{-1}\end{array}$ & $\begin{array}{l}\text { Correlation } \\
\text { coefficient }\end{array}$ \\
\hline 10 & 0.0107 & -0.0053 & 0.9993 \\
\hline 20 & 0.0182 & -0.0078 & 0.9990 \\
\hline 30 & 0.0296 & -0.0230 & 0.9999 \\
\hline 40 & 0.0426 & -0.0423 & 0.998 \\
\hline
\end{tabular}

Calibration equation: $1 / \tau=S[\mathrm{Mn}]+B$ in a range of $2-15 \mu \mathrm{g} \mathrm{L}^{-1}$ of $\mathrm{Mn}(\mathrm{II})$.

$$
B=-1.26 \times 10^{-3} T+1.20 \times 10^{-2} \quad(r=-0.96),
$$

in a range of $10-40^{\circ} \mathrm{C}$. The minus value in Eq. (12) is caused by a non-linear part of the calibration curve at lower [Mn]. Equations (10), (11) and (12) give

$$
\begin{gathered}
1 / \tau=\left(1.07 \times 10^{-3} T-1.5 \times 10^{-3}\right)[\mathrm{Mn}]- \\
1.26 \times 10^{-3} T+1.20 \times 10^{-2} .
\end{gathered}
$$

When $\tau=\tau_{\mathrm{f}}$ at $T=T_{\mathrm{f}}$, Eq. (13) becomes

$$
\begin{gathered}
1 / \tau_{\mathrm{f}}=\left(1.07 \times 10^{-3} T_{\mathrm{f}}-1.5 \times 10^{-3}\right)[\mathrm{Mn}]- \\
1.26 \times 10^{-3} T_{\mathrm{f}}+1.20 \times 10^{-2} .
\end{gathered}
$$

From Eqs. (13) and (14),

$$
\begin{gathered}
1 / \tau_{\mathrm{f}}=\left(1.07 \times 10^{-3} T_{\mathrm{f}}-1.5 \times 10^{-3}\right)\left(1 / \tau+1.26 \times 10^{-3} T-\right. \\
\left.1.20 \times 10^{-2}\right) /\left(1.07 \times 10^{-3} T-1.5 \times 10^{-3}\right)- \\
1.26 \times 10^{-3} T_{\mathrm{f}}+1.20 \times 10^{-2} .
\end{gathered}
$$

This equation gives values of $1 / \tau$ at $T_{\mathrm{f}}\left(30^{\circ} \mathrm{C}\right.$ for the proposed method) from those at various on-site temperatures $(T)$. It is noted that the calculation of $1 / \tau_{\mathrm{f}}$ requires only two values: the on-site reaction temperature and measured $1 / \tau$. Therefore, control of the reaction temperature or the construction of the calibration curve is not necessary in on-site work.

\section{Analytical performances}

The concentration of MG is restricted in the absorbance measurement. Figure 3 shows the effect of its concentration on $\delta$ for the reagent blank. An increase in the concentration of MG shortened the length of the induction period, and was effective to minimize the analytical time. On the other hand, the value of $\delta$ did not decrease over $11 \mu \mathrm{M}$ of MG. Therefore, $22 \mu \mathrm{M}$ of MG was adopted as an optimized condition. The other reaction conditions were based on those optimized previously. ${ }^{8}$ For the laboratory determination, a fixed absorbance value of 1.60 was chosen as a compromise between the linearity of the calibration curve and the rapidity of the analysis. The calibration curve was linear in a range of $2-45 \mu \mathrm{g} \mathrm{L}^{-1}$ of $\mathrm{Mn}$ (II) with $r=0.999$. The determination of manganese at less than $2 \mu \mathrm{g} \mathrm{L}^{-1}$ was not recommended, because of the long reaction time of over $30 \mathrm{~min}$. The error of determination was $0.2 \mu \mathrm{g} \mathrm{L}^{-1}$ for five determinations of $2 \mu \mathrm{g} \mathrm{L}^{-1}$ of $\mathrm{Mn}(\mathrm{II})$. The interference from foreign ions was investigated for $\mathrm{Al}(\mathrm{III}), \mathrm{Fe}(\mathrm{II}), \mathrm{Fe}(\mathrm{III}), \mathrm{Cu}(\mathrm{II})$ and $\mathrm{I}^{-}$, which interfered with the determination by a previous method. ${ }^{8}$ No interference was found for $500 \mu \mathrm{g} \mathrm{L}^{-1}$ of $\mathrm{Fe}$ (III) in the determination of $5 \mu \mathrm{g} \mathrm{L}^{-1}$ of $\mathrm{Mn}$ (II) within an error of $5 \%$. For $\mathrm{Cu}(\mathrm{II})$ or $\mathrm{I}^{-}, 100 \mu \mathrm{g} \mathrm{L}^{-1}$ did not interfere with the determination. These results suggested no interference for many natural fresh-water samples. ${ }^{4}$ A positive error was found for $\mathrm{Al}(\mathrm{III})$ over $50 \mu \mathrm{g} \mathrm{L}^{-1}$. It became negligible up to $300 \mu \mathrm{g} \mathrm{L}^{-1}$ in the

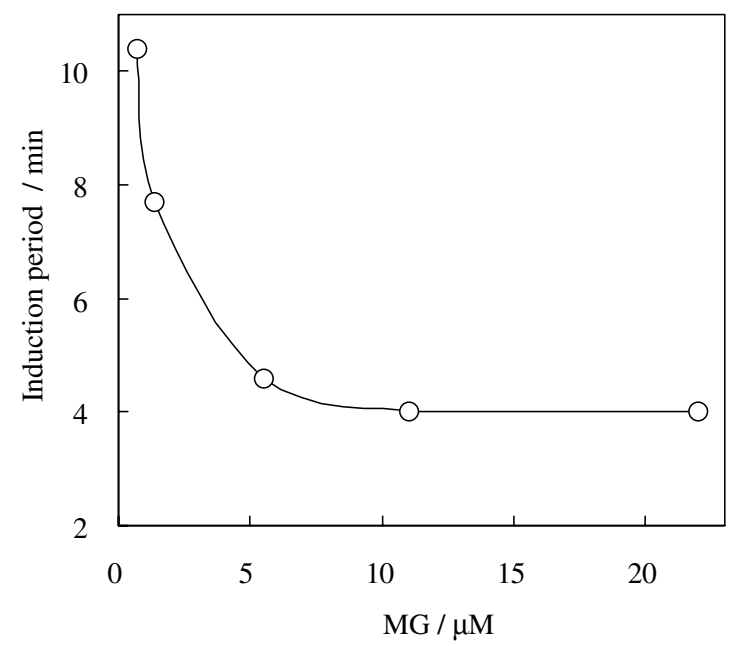

Fig. 3 Effect of the concentration of MG on the induction period for the reagent blank under the reaction conditions shown in Fig. 1.

presence of $100 \mathrm{mg} \mathrm{L}^{-1}$ of $\mathrm{F}^{-}$. Therefore, if necessary, a sodium fluoride solution was added to the sample for masking $\mathrm{Al}(\mathrm{III})$. A positive error of $10 \%$ was found in the presence of $10 \mu \mathrm{g} \mathrm{L}^{-1}$ of $\mathrm{Fe}(\mathrm{II})$. Fortunately, most the surface-water samples contain dissolved oxygen, which is oxidative to $\mathrm{Fe}(\mathrm{II})$. The neutralization of an acidified sample increases the concentration of salts. It generally changes the ion strength of the reacting solution, and thereby influences the reaction kinetics. For example, the presence of $0.03 \mathrm{M} \mathrm{NaNO}_{3}$ increased about $30 \%$ in the slope of the calibration curve. Therefore, for matrix matching, the same amounts of acid and $\mathrm{NaOH}$ for the sample solution were added in the standard solution for constructing the calibration curve.

The spectrophotometer and the laboratory-made colorimeter indicated different absorbance values for the same reaction. It was probably caused by their different optical resolutions, as discussed for different dye solutions. ${ }^{9}$ The absorbance value for the colorimeter was 0.785 at the reaction time giving 1.60 for the spectrophotometer under the same reaction conditions at room temperature. The same calibration curve for $1 / \tau$ was obtained by measuring $\tau$ at 0.785 for the colorimeter, and at 1.60 for the spectrophotometer. Therefore, the measurement of $\tau$ in the on-site determination was carried out at an absorbance value of 0.785 . For the on-site method at a reaction temperature of about $25^{\circ} \mathrm{C}$, a linear calibration curve was obtained in the range of $2-20 \mu \mathrm{g} \mathrm{L}^{-1}$ of $\mathrm{Mn}$ (II) with $r=0.999$. In using a calibration curve prepared on-site, the value of the determination error was the same as that obtained by the laboratory determination method. The calculation of the $1 / \tau$ value at $30^{\circ} \mathrm{C}$ from that at an on-site temperature $\left(18^{\circ} \mathrm{C}\right)$ introduced analytical errors within $1 \mu \mathrm{g} \mathrm{L}^{-1}$ for the determination of 2 to $20 \mu \mathrm{g} \mathrm{L}^{-1}$ of $\mathrm{Mn}(\mathrm{II})$. Therefore, $3 \mu \mathrm{g} \mathrm{L}^{-1}$ was estimated as being the maximum practical detection limit.

\section{Analysis of fresh water samples}

River-, lake- and tap-water samples were collected in Kofu, Japan. Solid particles in the sample were eliminated by on-site filtration through a membrane filter with a pore size of $0.45 \mu \mathrm{m}$. After on-site analyses, the samples were stored at about $5^{\circ} \mathrm{C}$ in an ice box and analyzed by the laboratory determination method and/or a graphite furnace atomic absorption spectrometry (GFAAS) within one day. A certified reference material (JSAC 0302, spiked and acidified river water) was purchased from 
Table 2 Analytical results of manganese in fresh-water samples

\begin{tabular}{|c|c|c|c|c|}
\hline \multirow{2}{*}{ Sample } & \multirow{2}{*}{$\begin{array}{c}\text { Sample } \\
\text { taken }^{\text {b }} \\
\mathrm{ml}\end{array}$} & \multicolumn{3}{|c|}{ Concentration of manganese $/ \mu \mathrm{g} \mathrm{L}^{-1}$} \\
\hline & & $\begin{array}{l}\text { On-site } \\
\text { method }\end{array}$ & $\begin{array}{l}\text { Laboratory } \\
\text { method }\end{array}$ & GFAAS $^{c}$ \\
\hline Nigorigawa river $\mathrm{A}^{\mathrm{d}}$ & 0.4 & - & 132,121 & $122 \pm 4$ \\
\hline $\begin{array}{l}\text { Nigorigawa river } B^{d} \\
(\mathrm{pH} 7.4)\end{array}$ & 0.4 & $209 \pm 10$ & - & $193 \pm 4$ \\
\hline $\begin{array}{l}\text { Arakawa river } \\
(\mathrm{pH} 7.4)\end{array}$ & 2.5 & $16 \pm 1$ & 14 & $15.2 \pm 0.3$ \\
\hline Fujikawa river & 2 & 5.2 & 5.0 & - \\
\hline $\begin{array}{l}\text { River water } \\
\text { reference material }\end{array}$ & 2.5 & $4.7 \pm 0.2$ & $\begin{array}{l}4.8 \pm 0.2 \\
5.1 \pm 0.1^{\mathrm{f}}\end{array}$ & $5.1 \pm 0.2$ \\
\hline $\begin{array}{l}\text { Chiyodako lake } \\
\text { (pH 7.5) }\end{array}$ & 2.5 & $45 \pm 2$ & - & $44 \pm 2$ \\
\hline Tap water & 2.5 & $<5$ & $<1$ & $<1$ \\
\hline
\end{tabular}

a. Average \pm standard deviation was obtained by three determinations. b. For the on-site and laboratory methods.

c. GFAAS denotes graphite furnace atomic absorption spectrometry.

d. Collected in separate months.

e. JSAC 0302 with the certified value of $5.0 \pm 0.1 \mu \mathrm{g} \mathrm{L}-1$ for manganese.

f. Masked with $\mathrm{NaF}$.

Tama Chemicals and analyzed after neutralizing with the $\mathrm{NaOH}$ solution. Table 2 gives the analytical results obtained by the above-mentioned three methods. For most samples, the analytical result obtained by the proposed on-site method agreed with those by the other two methods within an error of $10 \%$. The reliability of the method was confirmed by the result for the river reference material. The highest concentrations of manganese found for Nigorigawa river indicate the pollution of this river. ${ }^{14}$ Higher concentrations of manganese for Chiyodako lake suggest the requirement of monitoring for water quality control. Manganese was not detected for tap water. This result was consistent with that obtained by the other two methods.

\section{Conclusion}

A simple catalytic method was proposed for the on-site determination of trace manganese in fresh-water samples. Based on a kinetic approach, a kinetic parameter for the determination and an algorithm for calculating values of this parameter without control of the reaction temperature were studied for on-site determination. Manganese can be determined in the range of $3-20 \mu \mathrm{g} \mathrm{L}^{-1}$ within an error of $1 \mu \mathrm{g} \mathrm{L}^{-1}$. In the laboratory, manganese can be determined with an error of $0.2 \mu \mathrm{g} \mathrm{L}^{-1}$ by the spectrophotometric procedure under a controlled temperature at $30^{\circ} \mathrm{C}$. The on-site method was applicable to river-, lake- and tap-water samples.

\section{Acknowledgements}

This work was partly supported by a Grant-in-Aid for Scientific Research No. 19550084 from the Ministry of Education, Science, Sports and Culture of Japan.

\section{References}

1. WHO, "Guidelines for Drinking-Water Quality, Vol. 1 Recommendations", 2008, WHO Press, Geneva, 398.

2. U. S. Environmental Protection Agency, "Secondary Drinking Water Regulations: Guideline for Nuisance Chemicals", 1992, EPA-810-K-92-001, http://water.epa. gov/drink/contaminants/secondarystandards.cfm.

3. Notification No. 1010004, 2003, Ministry of Health, Labor and Welfare, Japan.

4. C. Reimann and P. de Caritat, "Chemical Elements in the Environment, Factsheets for the Geochemist and Environmental Scientist", 1998, Springer, Berlin.

5. DR/890 Colorimeter, Procedures Manual, Method 8149. Catalog No. 48470-22, 275, 2009, Hach Company, Loveland, CO.

6. A. Goodwin, A. L. Lawrence, C. E. Banks, F. Wantz, D. Omanović, Š. Komorsly-Lović, and R. G. Compton, Anal. Chim. Acta, 2005, 533, 141.

7. M. K. Beklemishev, T. A. Stoyan, and I. F. Dolmanova, Analyst [London], 1997, 122, 1161.

8. T. Fukasawa, S. Kawakubo, and M. Mochizuki, Bunseki Kagaku, 1983, 32, 669.

9. Y. Suzuki, T. Aruga, H. Kuwahara, M. Kitamura, T. Kuwabara, S. Kawakubo, and M. Iwatsuki, Anal. Sci., 2004, 20, 975.

10. H. A. Mottola and C. R. Harrison, Talanta, 1971, 18, 683.

11. A. Granzow, A. Wilson, and F. Ramirez, J. Am. Chem. Soc., 1974, 96, 2454.

12. T. Fukasawa, M. Iwatsuki, S. Kawakubo, and M. Mochizuki, Mikrochim. Acta, 1986, 1986III, 71.

13. C. L. Zhang, S. Kawakubo, and T. Fukasawa, Anal. Chim. Acta, 1989, 217, 23.

14. S. Kawakubo, K. Ogihara, M. Watanabe, and M. Iwatsuki, Field Anal. Chem. Technol., 1999, 3, 29. 